J. Sustain. Wireless Syst.

Vol.02/ No. 1

Pages: 1- 12

http://irojournals.com/irosws/

DOI: https://doi.org/10.36548/jsws.2020.1.001

\title{
A Compact 3.1- 18.8 GHz Triple Band Notched UWB Antenna for mobileUWB Applications
}

\author{
V N Koteswara Rao Devana ${ }^{1}$, Dr. A. Maheswara Rao ${ }^{2}$ \\ ${ }^{1}$ Research Scholar, \\ Department of ECE, JNTUA, \\ Anathapuramu, A.P, India. \\ dvnkrao@gmail.com \\ ${ }^{2}$ Associate Professor \\ ECE of Department, PBRVITS, \\ Kavali, A.P, India. \\ Amreddy73@gmail.com
}

\begin{abstract}
A compact triple band notched tapered microstrip fed Ultrawideband (UWB) antenna for wireless communication applications in C, X and Ku bands is proposed. The antenna having a compact size of $16 \times 26 \mathrm{~mm}^{2}$, consisting of an elliptical patch and a truncated ground structure to achieve impedance of $-10 \mathrm{~dB}$ bandwidth of $3.1 \mathrm{GHz}$ to $18.8 \mathrm{GHz}$. Triple band notched characteristics are obtained from 3.7 GHz to $4.2 \mathrm{GHz}$ for $\mathrm{C}$ band, 5.18 GHz to $5.85 \mathrm{GHz}$ for Wireless Local Area Network (WLAN) and $8 \mathrm{GHz}$ to $8.4 \mathrm{GHz}$ for $\mathrm{X}$ band applications associated with the satellite communication, fabricating three inverted slots that are U-shaped in the patch of elliptical form. Good agreement between theoretical and the practical results achieved through simulation of the antenna proposed is a compatible candidate for portable ultra-wide band applications.
\end{abstract}

Keywords: Band Notched; Microstrip Fed; Monopole; Slot; Ultra wide band.

\section{Introduction}

In 2002, the band of frequencies ranging from 3.1 to $10.6 \mathrm{GHz}$ is allocated applications of the UWB that are unlicensed by the FCC [1], for the EIRP (effective isotropic radiated power) of $41.3 \mathrm{dBm} / \mathrm{MHz}$. the ultrawide band antennas are the fundamental equipment of the unwired systems of communication, so careful attention is necessitated for the designing of the ultra-wide band antennas as the antenna requires low profile, compact size and low cost, radiation patterns that are stable with the simple structures. To achieve these characteristics, various microstrip antennas were reported with different shapes such as rectangular patch with steps [2], circular shaped [3], a heart shaped [4], and cutting different shapes of slots in the ground plane [5].

However, antenna designs for UWB systems face severe Electro Magnetic Interference (EMI) problems

ISSN: 2582-3167 (online) 
J. Sustain. Wireless Syst.

Vol.02/ No. 1

Pages: $1-12$

http://irojournals.com/irosws/

DOI: https://doi.org/10.36548/jsws.2020.1.001

with narrow band systems like Worldwide Microwave Access Interportability WiMAX (and X-band satellite communication Hence, to alleviate the EMI of ultra-wide band systems with the systems that are of narrow band, ultra-wide band antennas with multiple bands that are notched are put forth in the paper. The functionalities for the notched band are generated by introducing y dual slots that are U- shaped [6], C- shaped slot [7], meandered shaped [8] in the patch for radiating and V-shaped slots [9] in the ground.

The present work is focusing on the design of an elliptical shaped monopole antenna to cover the $-10 \mathrm{~dB}$ impedance bandwidth of UWB, $\mathrm{X}$ and Ku bands with triple band notch characteristics in UWB band. The fractional impedance bandwidth of more than $143 \%$ of proposed antenna is achieved by fractional ground plane and a tapered microstrip feed line. [10-16].

\section{Design Methodology}

The Figure 1 and Figure 2 shows the proposed ultra-wide notched band antenna's geometry.

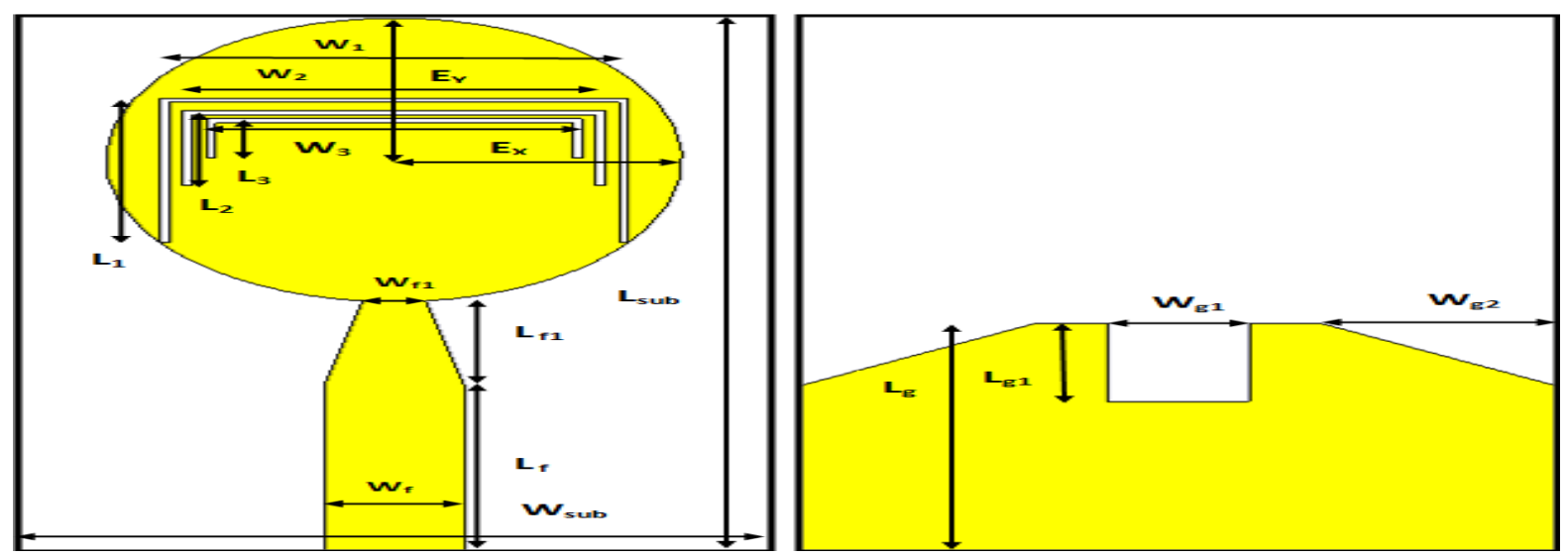

(A) View from Top

(B) View from Bottom

Figure 1 Proposed Antenna's Geometry

ISSN: 2582-3167 (online) 
J. Sustain. Wireless Syst.

Vol.02/ No. 1

Pages: $1-12$

http://irojournals.com/irosws/

DOI: https://doi.org/10.36548/jsws.2020.1.001

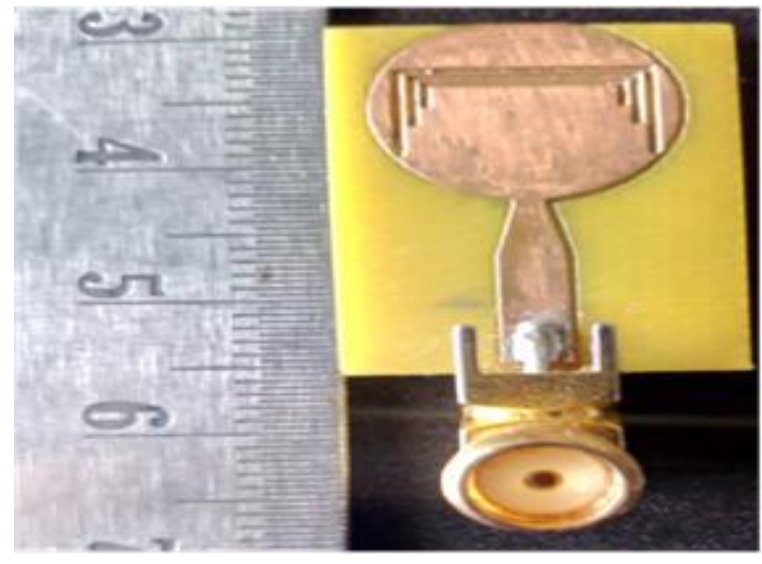

(A) View from Top

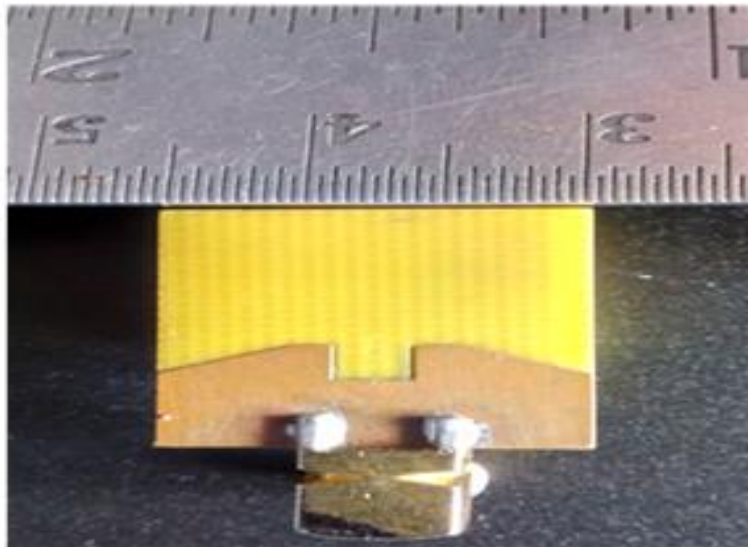

(B) View from Bottom

Figure 2 Snap Shot of Fabricated-Antenna

An elliptical shaped patch is reproduced on substrate (FR-4) of dimension $16 \times 26 \mathrm{~mm}^{2}$. The elliptical patch is fed with a $3 \times 12.2 \mathrm{~mm}^{2}$ size tapered microstrip feed line, designed to be matched with a $50 \Omega$ SMA connector. The optimal magnitudes of the ultra-wide band antenna put forth were as given below: $\mathrm{W}_{\text {sub }}=16.1 \mathrm{~mm}, \mathrm{~L}_{\mathrm{sub}}=26$ millimeter, $\mathrm{E}_{\mathrm{x}}=6.15$ millimeter, $\mathrm{E}_{\mathrm{Y}}=6.9$ millimeter, $\mathrm{W}_{\mathrm{f}}=3$ millimeter, $\mathrm{L}_{\mathrm{f}}=8$ millimeter, $\mathrm{W}_{\mathrm{fl}}=1.3$ millimeter, $\mathrm{L}_{\mathrm{fl}}=4.2$ millimeter, $\mathrm{W}_{1}=10$ millimeter, $\mathrm{L}_{1}=6.3$ millimeter, $\mathrm{W}_{2}=9 \mathrm{~mm}$, $\mathrm{L}_{2}=3.45 \mathrm{~mm}, \mathrm{~W}_{3}=8 \mathrm{~mm}, \mathrm{~L}_{3}=1.7 \mathrm{~mm}, \mathrm{~L}_{\mathrm{g}}=11.05 \mathrm{~mm}, \mathrm{~L}_{\mathrm{g} 1}=3.8 \mathrm{~mm}, \mathrm{~W}_{\mathrm{g} 1}=3 \mathrm{~mm}$, and $\mathrm{W}_{\mathrm{g} 2}=5 \mathrm{~mm}$.

\section{STUDY OF THE PROPOSED ANTENNA- PARAMETRIC DETAILS}

The procedure of developing triple UWB monopole antenna-notched antenna to cover $\mathrm{C}, \mathrm{X}$, and $\mathrm{Ku}$ bands is discussed with parametric study. Firstly, the reference elliptical UWB antenna with truncated ground structure as shown in Figure 3 (A), Antenna 1 is designed to cover $-10.1 \mathrm{~dB}$ BW of 3.12 to $19.66 \mathrm{GHz}$ suitable for applications of bands $\mathrm{Ku}, \mathrm{C}$, and $\mathrm{X}$. 
J. Sustain. Wireless Syst.

Vol.02/ No. 1

Pages: 1- 12

http://irojournals.com/irosws/

DOI: https://doi.org/10.36548/jsws.2020.1.001

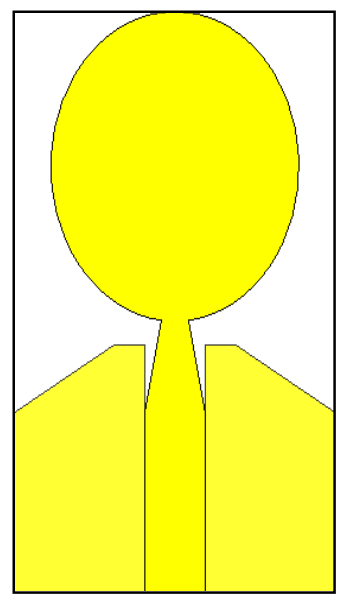

(A) $1^{\text {st }}$ antenna

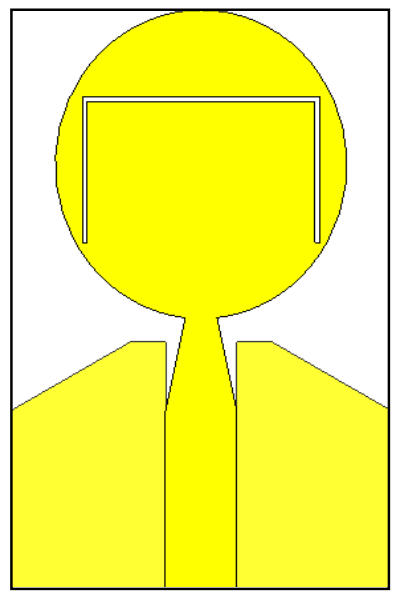

(B) $2^{\text {nd }}$ antenna

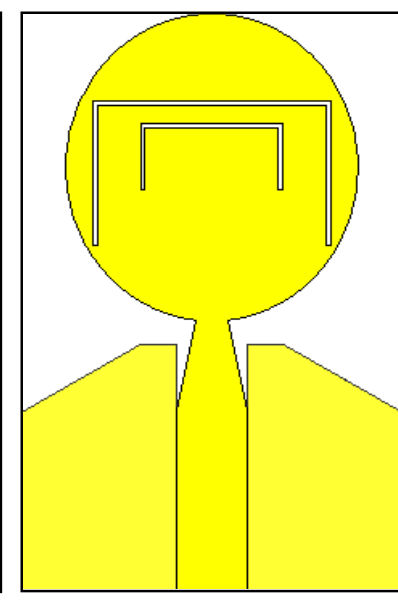

(C) $3^{\text {rd }}$ antenna

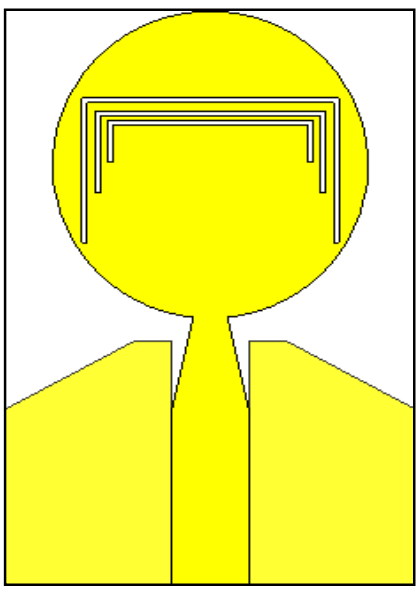

(D) $4^{\text {th }}$ antenna

Figure 3 Proffered Step By Step Implementation.

The triple band notch characteristics of the antenna proffered is achieved by utilizing three inverted slots shaped into U. The U- shaped slot that is inverted on the upper side introduces a band notch for C-band, the middle one for WLAN and the slot U-shaped and lower inverted for X-band. The notched frequencies of the proposed antenna approximated mathematically as given by [17],

$$
f_{r} \approx \frac{c}{\lambda_{g} \times \sqrt{\varepsilon_{e f f}}} \approx \frac{c}{2 L_{n} \times \sqrt{\varepsilon_{e f f}}}
$$

Where $\varepsilon_{\text {eff }}$ - effective- dielectric constant, while $c$ - light speed, and $f_{r}$ is notched frequency associated with the total effective length, $L_{n}$ of the inverted $U$ - shaped slots. Here, the total effective length of the slots $\mathrm{L}_{\mathrm{n}}$ is equal to $\frac{\lambda_{g}}{2}\left(\lambda_{g}\right.$ is the guided wavelength at $f_{r}$ ). Each slot of the proposed antenna works as a half wavelength resonator. The magnitude of return loss $\left(S_{11}\right)$ plot for first, second, third and fourth antennas are shown in Figure 4. 
J. Sustain. Wireless Syst.

Vol.02/ No. 1

Pages: $1-12$

http://irojournals.com/irosws/

DOI: https://doi.org/10.36548/jsws.2020.1.001

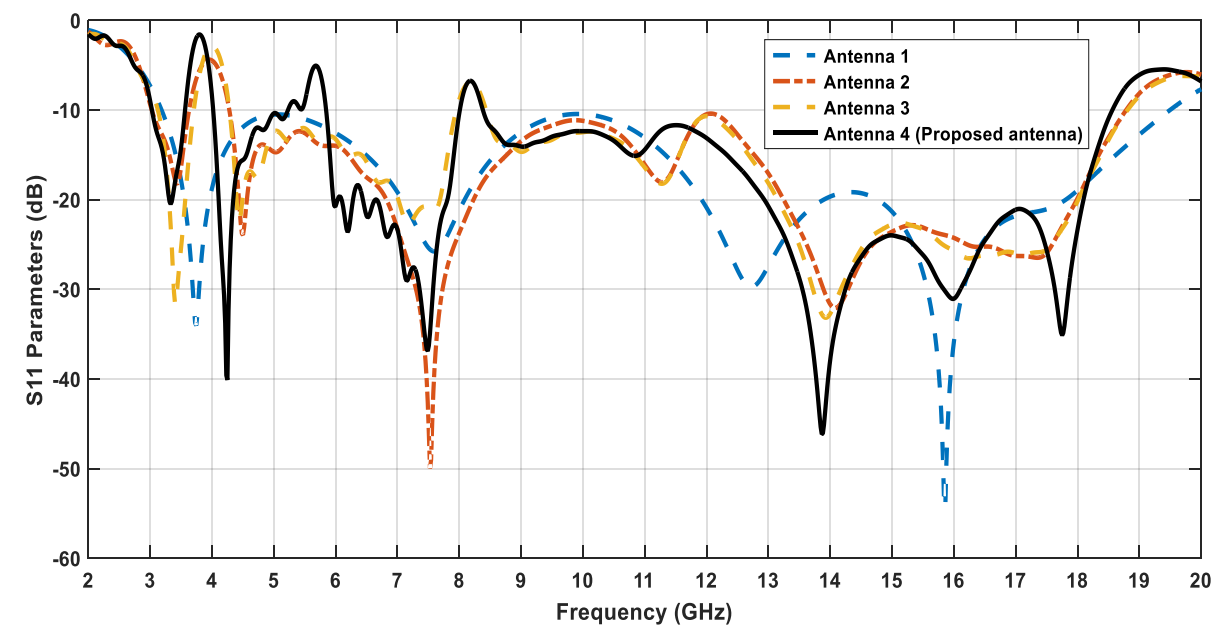

Figure 4 Return-Loss magnitude $\left(S_{11}\right)$ plot of antenna proffered in different stages

Antenna 2 structure creates a notch for the band $\mathrm{C}$ at $f_{r}=3.74 \mathrm{GHz}$ and by etching $\mathrm{U}$-shaped slot that is upper inverted with optimized physical length $L_{n}=22.6 \mathrm{~mm}$. The structure Antenna 3 creates a notch band centered at $8.1 \mathrm{GHz}$ for $\mathrm{X}$ band satellite communications by etching lower inverted U-shaped slot with optimized physical length $\mathrm{L}_{\mathrm{n}}=11.4 \mathrm{~mm}$. The Antenna 4 structure creates notch band centered at $5.6 \mathrm{GHz}$ for WLAN frequency by introducing middle inverted U- shaped slot with optimized physical length $\mathrm{L}_{\mathrm{n}}=15.9 \mathrm{~mm}$.

The parametric study of the planned triple notch-band antenna for each band notch is studied by dimension that are unpredictable of a particular slot length at a period however keeping extra slot lengths Stable. The return loss plot for variation in individual total lengths of the slots $L_{n}$ are shown in Figure 5(A) - (C).

ISSN: 2582-3167 (online) 
J. Sustain. Wireless Syst.

Vol.02/ No. 1

Pages: 1- 12

http://irojournals.com/irosws/

DOI: https://doi.org/10.36548/jsws.2020.1.001

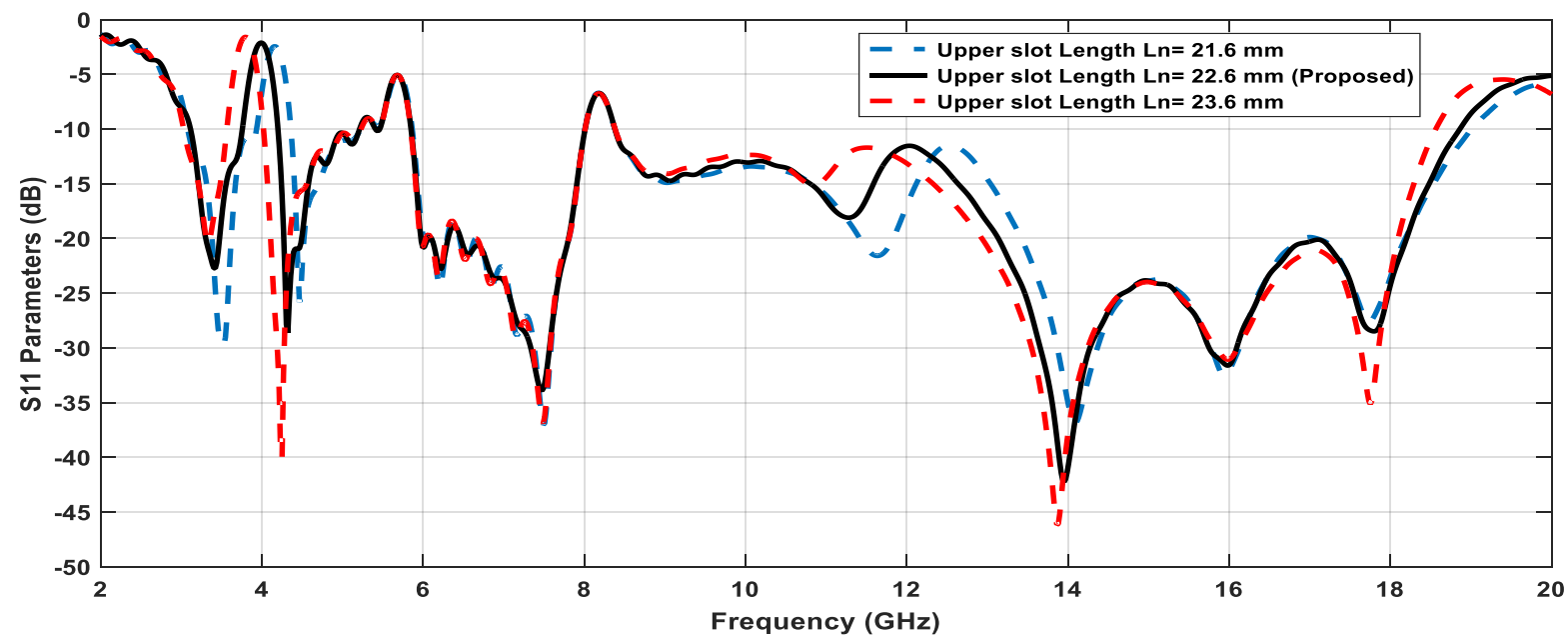

(A)

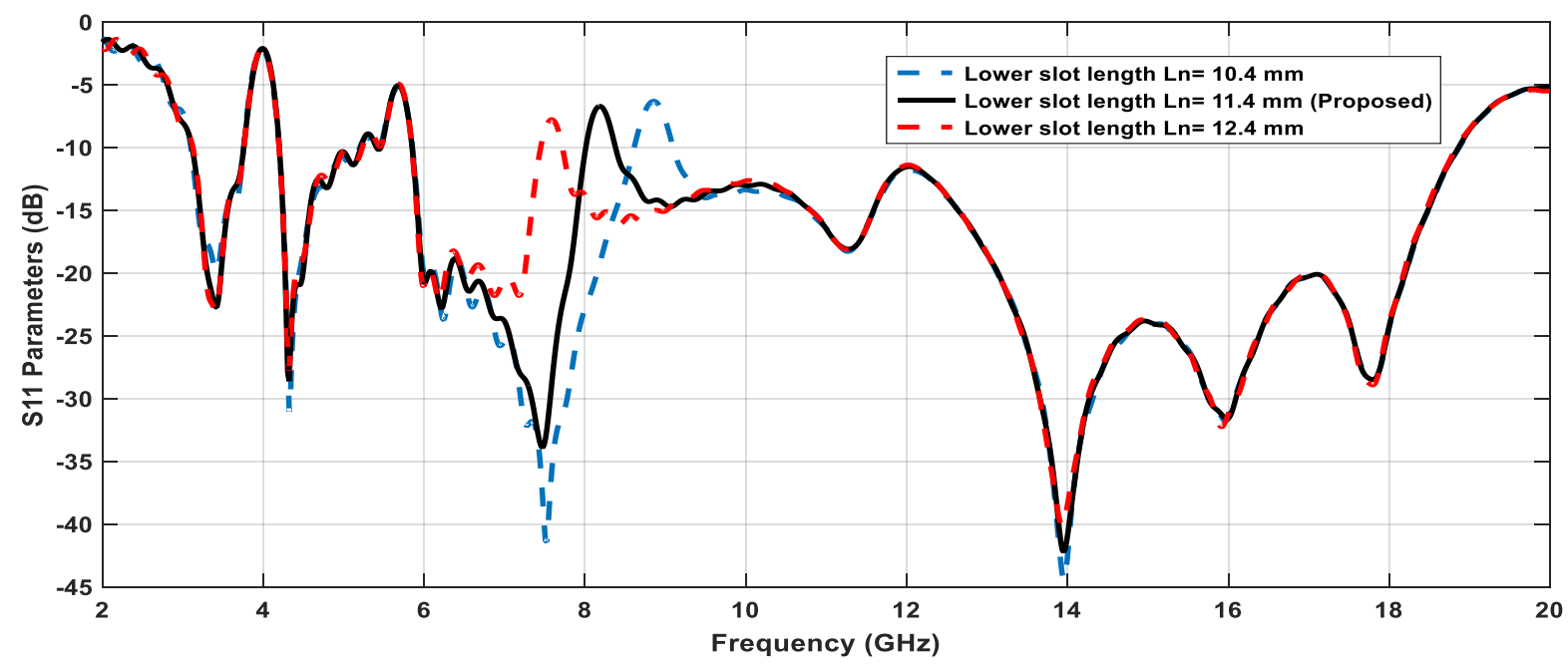

(B) 
J. Sustain. Wireless Syst.

Vol.02/ No. 1

Pages: $1-12$

http://irojournals.com/irosws/

DOI: https://doi.org/10.36548/jsws.2020.1.001

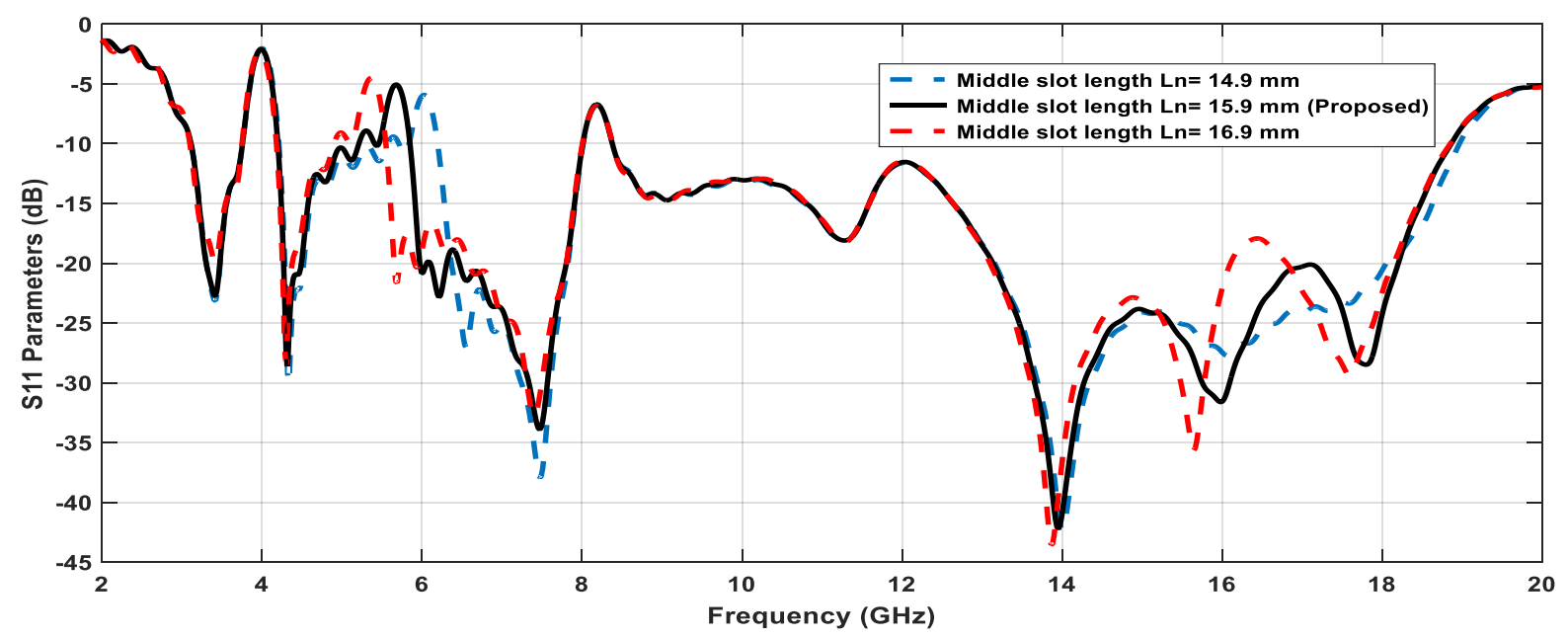

(C)

Figure 5 Proffered antenna return loss with different slot lengths (A) Upper slot (B) Lower slot (C)

Middle slot

From Figure 5(A) - (C), it is observed that variation in length of each slot shifts the centre frequency of notch band. The variation of length of an individual slot almost does not disturb the centre frequencies of other band notches. Thus, each notched band frequency is regulated adjusting the average length of individuals and location un-affecting the other notched bands.

\section{RESULTS AND DISCUSSION}

The practical and the theoretical return loss $\left(S_{11}\right)$ plot of the proposed feeler is depicted in Figure 6 . The electrical performance of the feeler is measured using the Anritsu MS2037C/2 network analyzer gain and the gains of the antennas of the reference and the proposed antennas are for the frequencies 3.8, 1.93, and $8.3 \mathrm{GHz}$ are $-2.32,-1.52$ and -.95 respectively are displayed in Figure 7.

ISSN: 2582-3167 (online) 
J. Sustain. Wireless Syst.

Vol.02/ No. 1

Pages: $1-12$

http://irojournals.com/irosws/

DOI: https://doi.org/10.36548/jsws.2020.1.001

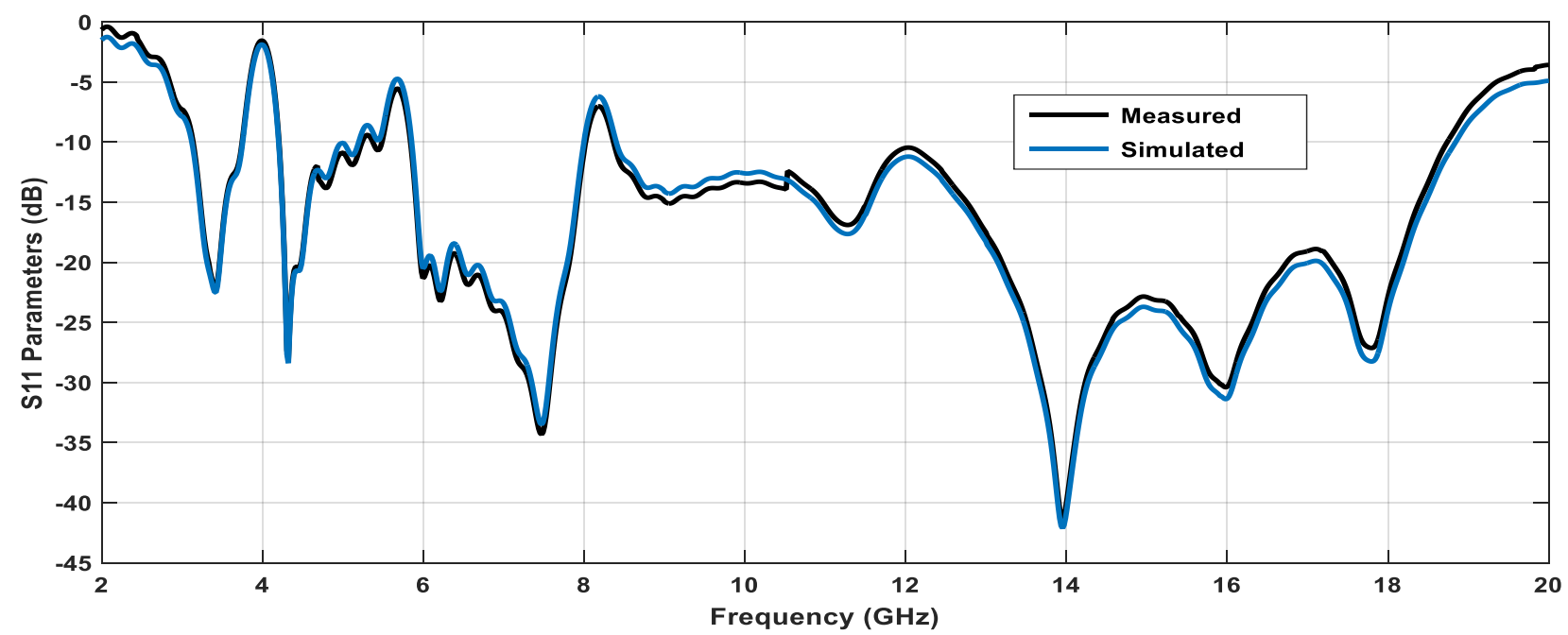

Figure 6 Theoretical and practical return loss $\left(S_{11}\right)$ plot of proffered antenna

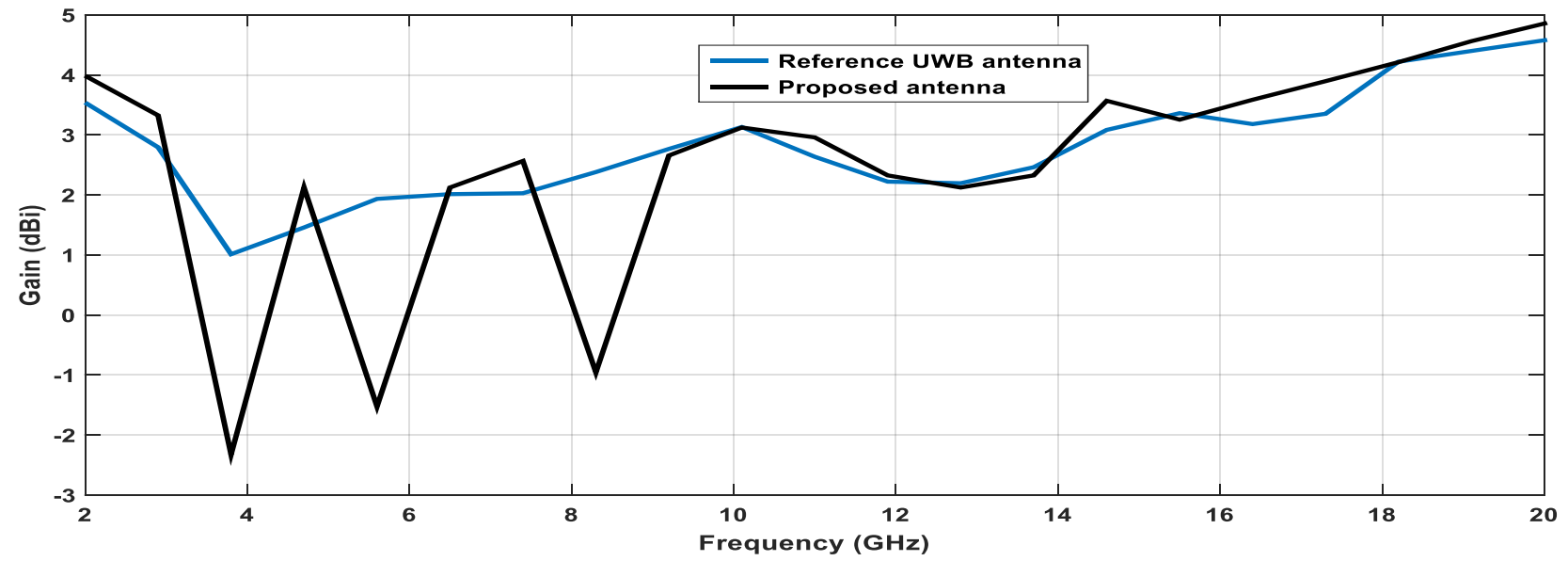

Figure 7 Measured peak gain of reference UWB and proposed antenna

The measured 2- proffered antenna, dimensional radiation $\mathrm{s}$ in $\mathrm{E}-$ plane and in $\mathrm{H}$ - plane.

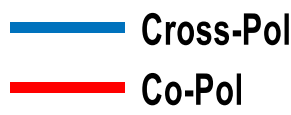

ISSN: 2582-3167 (online) 
J. Sustain. Wireless Syst.

Vol.02/ No. 1

Pages: $1-12$

http://irojournals.com/irosws/

DOI: https://doi.org/10.36548/jsws.2020.1.001

E- Plane
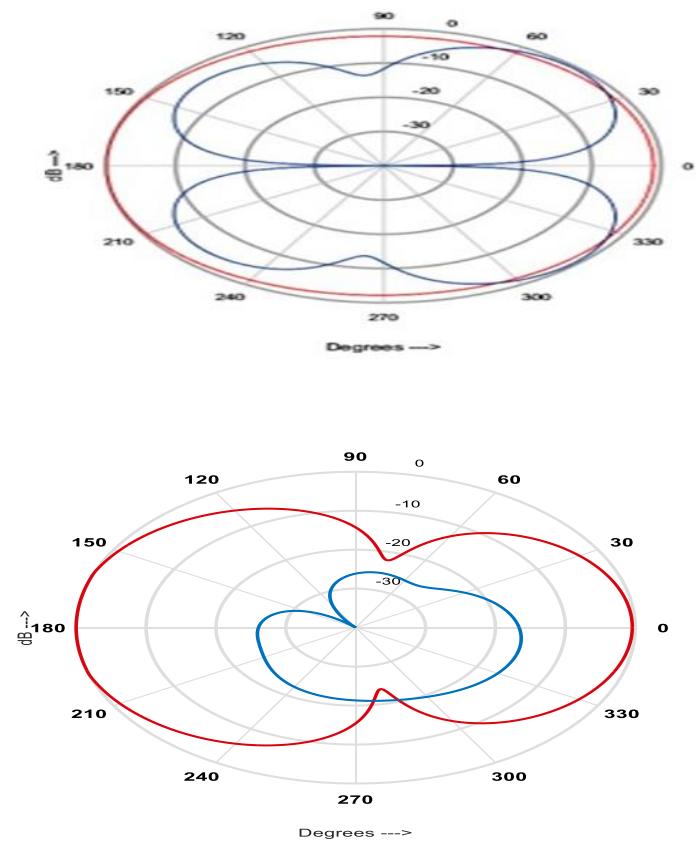

(B)

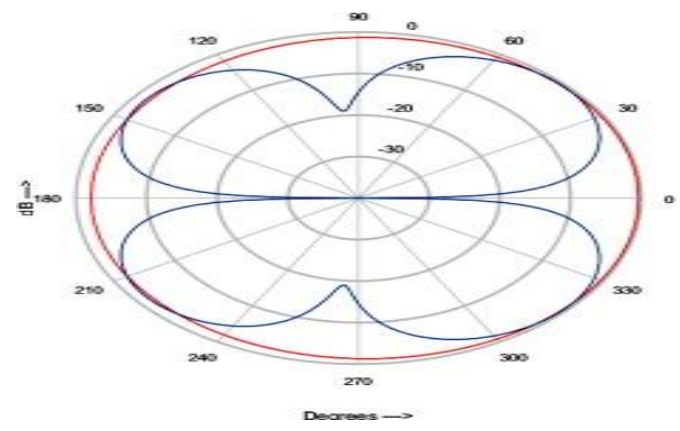

(C)
H- Plane

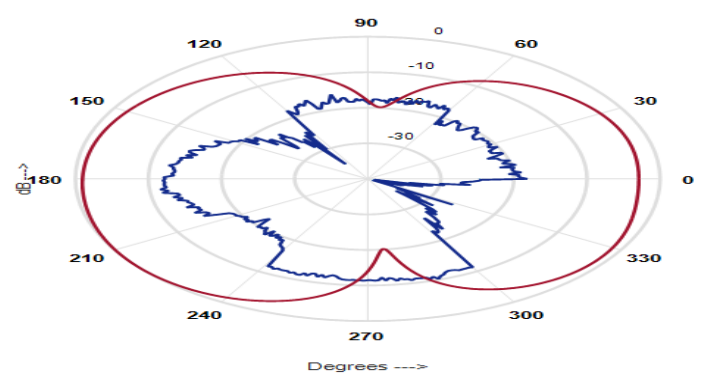

(A)
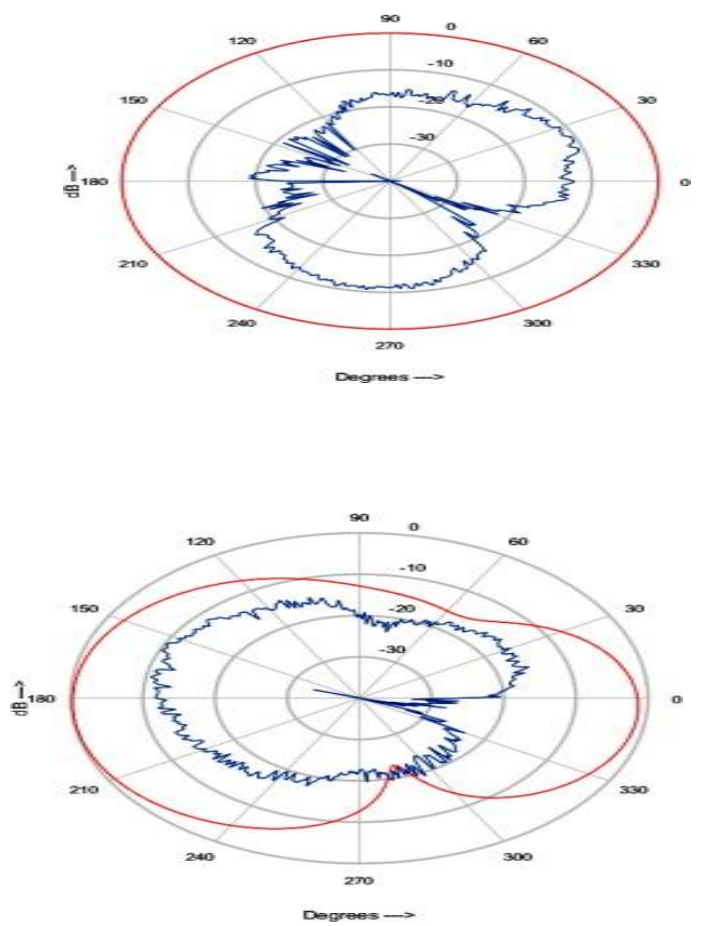

Figure 8 Measured 2- D radiation patterns for the proposed at (A) $3.42 \mathrm{GHz}$ (B) $4.34 \mathrm{GHz}$ (C) $7.52 \mathrm{GHz}$. 
J. Sustain. Wireless Syst.

Vol.02/ No. 1

Pages: $1-12$

http://irojournals.com/irosws/

DOI: https://doi.org/10.36548/jsws.2020.1.001

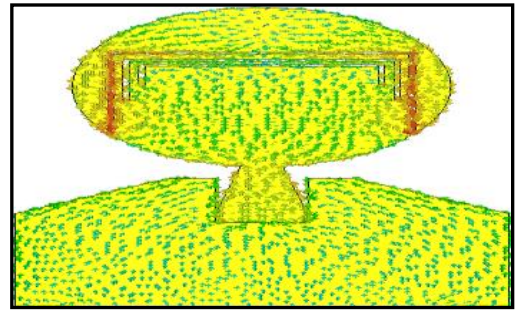

(A)

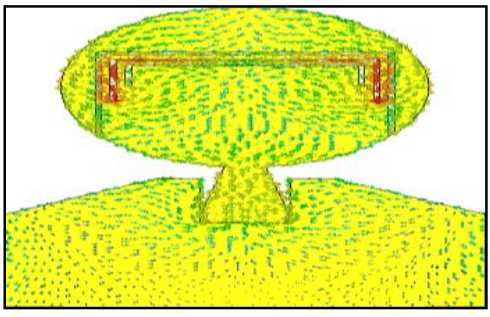

(B)

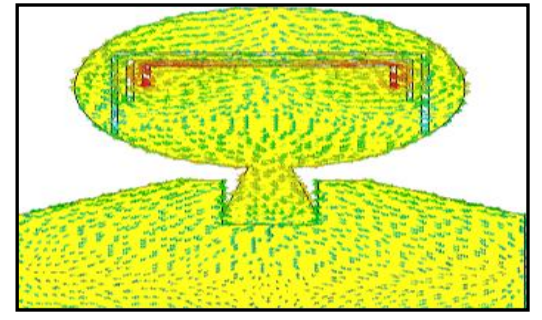

(C)

Figure 9 Simulated surface current distribution of the proposed antenna at (A) $4 \mathrm{GHz}$ (B) $5.7 \mathrm{GHz}$ (C) $8.22 \mathrm{GHz}$.

The simulated current distributions at notch band frequencies $4 \mathrm{GHz}, 5.7 \mathrm{GHz}$, and $8.22 \mathrm{GHz}$ are shown in Figure 9 (A) - (C).

From Figure 9 (A) - (C), it is observed that the surface currents in the area surrounded by the inverted Ushaped slots at different notch band frequencies 4, 5.7 and $8.22 \mathrm{GHz}$, are concentrated more (shown in red colored areas) than the area surrounded by the radiating patch. Also the direction of surface currents in these slots is opposite to the direction of surface currents in the radiating patch, which indicates that the cancellation of currents between the notch elements and the radiating patch weakens the effective radiation, and thus creates the band notches at $4 \mathrm{GHz}, 5.7 \mathrm{GHz}$, and $8.22 \mathrm{GHz}$.

\begin{tabular}{|c|c|c|c|}
\hline Ref. Antennas & $\begin{array}{c}\text { Size } \\
(\mathbf{m m} 2)\end{array}$ & $\begin{array}{c}\text { Area } \\
(\mathbf{m m} z)\end{array}$ & Notch Band (GHz) \\
\hline$[10]$ & $36 \times 38$ & 1368 & $\begin{array}{c}3.45-4,5.15-5.9,6.77-8,8.3-9.1, \\
9.3-10.6\end{array}$ \\
\hline [11] & $33 \times 28$ & 924 & $3.30-3.70,4.50-4.83,6.67-7.15$ \\
\hline$[12]$ & $30 \times 30$ & 900 & $3.39-3.88,5.11-5.97,8.0-8.71$ \\
\hline$[13]$ & $30 \times 30$ & 900 & $2.5,3.5,5.5$ \\
\hline$[14]$ & $20 \times 40$ & 800 & $3.9-4.1,5.0-5.7,6.6-6.9$ \\
\hline$[15]$ & $27 \times 27$ & 729 & $3.4,5.6,7.6$ \\
\hline$[16]$ & $25 \times 27$ & 675 & $3.3-3.7,5.15-5.875,7.1-7.6$ \\
\hline Proposed Antenna & $16 \times 26$ & 416 & $3.7-4.2,5.2-5.85,8-8.4$ \\
\hline
\end{tabular}

Table.1. Performance Comparison

ISSN: 2582-3167 (online)

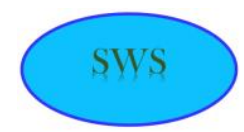


J. Sustain. Wireless Syst.

Vol.02/ No. 1

Pages: $1-12$

http://irojournals.com/irosws/

DOI: https://doi.org/10.36548/jsws.2020.1.001

\section{CONCLUSION}

A Compact triple band notched UWB monopole-antenna for application in bands $\mathrm{C}, \mathrm{X}$, and $\mathrm{Ku}$ is presented. the results observed for the antenna put forth in the paper has return loss $\left(\mathrm{S}_{11}\right)$ is $<-10 \mathrm{db}$ over the entire $\mathrm{C}, \mathrm{X}$, and $\mathrm{Ku}$ bands, except for the three notched bands at C-band (3.7-4.2 GHz), WLAN band (5.2- $5.85 \mathrm{GHz})$ and $\mathrm{X}$ - band $(8-8.4 \mathrm{GHz})$ in frequencies of UWB. The advantages of this antenna are, it covers a wide impedance bandwidth ranging from $3.1 \mathrm{GHz}$ to $18.8 \mathrm{GHz}$, its compactness, and triple band notch characteristics over UWB frequency range are achieved by simply three inverted U- shaped slots etched out on patch. The compact size of antenna makes it compatible for the mobile applications in ultra wide band.

\section{Acknowledgments}

V. N. Koteswara Rao. Devana and Dr. A. Maheswara Rao would like to express their gratitude towards University College of Engineering, JNTUA, Ananthapuramu, for their continuous support and encouragement during this work.

\section{ORICID}

V N Koteswara Rao Devana (iD) 0000-0001-5468-2172

\section{References}

[1] Langley, Eric B., and Millicent W. Ronnlund. "Federal Communications Commission Washington, DC 20554." (2010).

[2] Jung, Jihak, Wooyoung Choi, and Jaehoon Choi. "A small wideband microstrip-fed monopole antenna." IEEE microwave and wireless components letters 15, no. 10 (2005): 703-705..

[3] Liang, J., L. Guo, C. C. Chiau, X. Chen, and C. G. Parini. "Study of CPW-fed circular disc monopole antenna for ultra wideband applications." IEE Proceedings-Microwaves, Antennas and Propagation 152, no. 6 (2005): 520-526.

[4] Torres, CA Figueroa, JL Medina Monroy, H. Lobato Morales, RA Chávez Pérez, and A. Calvillo Tellez. "Heart shaped monopole antenna with defected ground plane for UWB applications." In 2014 11th International Conference on Electrical Engineering, Computing Science and Automatic Control (CCE), pp. 1-4. IEEE, 2014..

[5] Reddy, Gopi Shrikanth, Sanjeev Kumar Mishra, Shilpa U. Kharche, and Jayanta Mukherjee. "High

ISSN: 2582-3167 (online) 
J. Sustain. Wireless Syst.

Vol.02/ No. 1

Pages: $1-12$

http://irojournals.com/irosws/

DOI: https://doi.org/10.36548/jsws.2020.1.001

gain and low cross-polar compact printed elliptical monopole UWB antenna loaded with partial ground and parasitic patches." Progress In Electromagnetics Research 43 (2012): 151-167..

[6] Ojaroudi, M., Gh Ghanbari, N. Ojaroudi, and Ch Ghobadi. "Small square monopole antenna for UWB applications with variable frequency band-notch function." IEEE Antennas and Wireless Propagation Letters 8 (2009): 1061-1064.

[7] Fakharian, Mohammad M., Pejman Rezaei, and Aramn Azadi. "A planar UWB bat-shaped monopole antenna with dual band-notched for WiMAX/WLAN/DSRC." Wireless Personal Communications 81, no. 2 (2015): 881-891..

[8] Bialkowski, Marek E., and Amin M. Abbosh. "Design of UWB planar antenna with improved cutoff at the out-of-band frequencies." IEEE antennas and wireless propagation letters 7 (2008): 408410.

[9] Rostamzadeh, M., S. Mohamadi, J. Nourinia, Ch Ghobadi, and M. Ojaroudi. "Square monopole antenna for UWB applications with novel rod-shaped parasitic structures and novel V-shaped slots in the ground plane." IEEE Antennas and Wireless Propagation Letters 11 (2012): 446-449.

[10] Tang, Zhi-jun, Jie Zhan, and Xiao-feng Wu. "Compact triple band-notched printed antenna with multislots for UWB applications." Microwave And Optical Technology Letters 57, no. 9 (2015): 2056-2060.

[11] Wang, Ziyang, Jinhai Liu, and Yingzeng Yin. "Triple band-notched UWB antenna using novel asymmetrical resonators." AEU-International Journal of Electronics and Communications 70, no. 12 (2016): 1630-1636.

[12] Asadpor, Loghman, and MirHamed Rezvani. "Compact UWB CPW-fed Monopole Antenna with Variable Triple-band-notched Property." IETE Journal of Research (2018): 1-9.

[13] Tang, Chengpei. "A novel compact UWB antenna with triple notched bands using square ring short stub loaded resonator." Progress In Electromagnetics Research 58 (2016): 17-22.

[14] Emadian, Seyed Ramin, Javad Ahmadi-Shokouh, Changiz Ghobadi, and Javad Nourinia. "Study on frequency and impulse response of novel triple band notched UWB antenna in indoor environments." AEU-International Journal of Electronics and Communications 96 (2018): 93-106.

[15] Venkata, Sai Kiran, Muktikanta Rana, Pritam Singh Bakariya, Santanu Dwari, and Manas Sarkar. "Planar ultrawideband monopole antenna with tri-notch band characteristics." Progress In Electromagnetics Research 46 (2014): 163-170.

[16] Sohail, Amir, Khurram Saleem Alimgeer, Adnan Iftikhar, Bilal Ijaz, Kang Wook Kim, and Wahab Mohyuddin. "Dual notch band UWB antenna with improved notch characteristics." Microwave and Optical Technology Letters 60, no. 4 (2018): 925-930.

ISSN: 2582-3167 (online) 